\title{
Full-Thickness Skin Burn Caused by Radiofrequency Ablation of a Benign Thyroid Nodule
}

\author{
Stella Bernardi, ${ }^{1}$ Valentina Lanzilotti, ${ }^{1}$ Giovanni Papa, ${ }^{2}$ \\ Nicola Panizzo, ${ }^{2}$ Chiara Dobrinja, ${ }^{3}$ Bruno Fabris, ${ }^{1}$ and Fulvio Stacul ${ }^{4}$
}

\section{Dear Editor:}

Today, radiofrequency ablation (RFA) represents an effective therapeutic option for symptomatic benign thyroid nodules. The advantages of this outpatient treatment modality include reduced morbidity, no risk of cosmetic damage, and decreased costs (1). In Trieste, we started using RFA for symptomatic thyroid nodule ablation in 2012, and so far, 107 patients have been treated with this approach, with overall satisfactory results and a low complication rate (3\%), which is consistent with the literature (1-3). All the procedures were performed by the same operator, who is a well-trained radiologist, experienced in ultrasound (US), fine-needle aspiration biopsy, and RFA procedures. Nevertheless, in one of these patients $(0.9 \%)$, the procedure unexpectedly caused $(3,4)$ a third-degree skin burn. Here, we report our experience.

A healthy 34-year-old woman with a slim body habitus presented with a thyroid nodule located in the left inferior pole of the gland, which was partly plunging (Supplementary Fig. S1; Supplementary Data are available online at www .liebertpub.com/thy). On presentation, she complained of local cosmetic concerns, seeking advice on the best treatment modality of her nodule. The nodule measured $42 \mathrm{~mm} \times 40 \mathrm{~mm} \times$ $23 \mathrm{~mm}$ (Supplementary Fig. S2A) and was cytologically benign. Given that she refused surgery and met all the eligibility criteria for thyroid RFA (5), we suggested that she undergo this procedure. The patient was informed and prepared as already described $(1,2)$. Before the procedure, she underwent local anesthesia at the puncture site with $10 \mathrm{~mL}$ of $2 \%$ lidocaine, as well as conscious sedation with $2 \mathrm{mg}$ of midazolam.

To ablate the nodule, a monopolar electrode featuring a shaft length of $10 \mathrm{~cm}$ and an exposed tip length of $10 \mathrm{~mm}$ (RF AMICA_PROBE model RFH18100V1, HS Hospital Service $\mathrm{SpA}$, Italy) was inserted into the thyroid nodule under US guidance. In particular, due to the position of the nodule (Supplementary Fig. S1), the electrode was inserted directly into the nodule from above (direct approach), instead of reaching it through the thyroid isthmus (transisthmic ap- proach). We began by ablating the central areas of the nodule (Supplementary Fig. S2B) with an initial RF power of $30 \mathrm{~W}$, which was then increased to $40 \mathrm{~W}$. Then, in order to treat the other parts of the nodule, the electrode was moved and pulled slightly backward. Probably at that moment, the active needle tip must have come in close proximity to the skin with the power delivery possibly not switched off yet, so that a skin burn developed. The lesion was noticed by the operator immediately after it developed, and as soon as it was noticed the procedure was stopped, leaving most of the nodule untreated (Supplementary Fig. S2C). Otherwise, the patient did not perceive anything and she did not complain of pain during the skin injury because of the conscious sedation and local anesthesia. No other complications were encountered.

Initially, the lesion appeared as a full-thickness burn that surrounded the electrode puncture site, with a maximum diameter of $1.5 \mathrm{~cm}$ and a charred white necrotic core (Fig. 1A). The patient was seen by a plastic surgeon who recommended treatment with topical gentamicin sulfate and hyaluronic acid for the first week, in order to reduce the risk of bacterial colonization of the wound and to help tissue regeneration and wound healing. The following week, the patient started applying an activated charcoal cloth with silver. Then, after surgical debridement of the wound (Fig. 1B), the skin burn was treated with a collagen wound dressing for another two weeks. Overall, although this skin burn took more than one month to heal, its final appearance looked almost like the normal skin (Fig. 1C).

To our knowledge, this is the first report of a full-thickness skin burn caused by RFA of a benign thyroid nodule. The RFAinduced skin burns that have been reported so far were usually of first degree, and patients recovered within seven days (3-4). Here, we describe this clinical experience to raise awareness that RFA can also lead - although rarely - to full-thickness burns that take at least three weeks to heal and usually develop a scar, which may be severe. Patients should be informed of this extremely infrequent but regrettable possibility as well as its remedies, especially if they are undergoing RFA because of cosmetic concerns (and they want to avoid surgical scars).

\footnotetext{
Departments of ${ }^{1}$ Medical, Surgical, and Health Sciences, ${ }^{2}$ Plastic and Reconstructive Surgery, and ${ }^{3}$ General Surgery, University of Trieste, Cattinara Teaching Hospital, Trieste, Italy.

${ }^{4}$ Department of Radiology, Maggiore Hospital, Trieste, Italy.

(C) Bernardi et al., 2016 Published by Mary Ann Liebert, Inc. This Open Access article is distributed under the terms of the Creative Commons Attribution Noncommercial License (http://creativecommons.org/licenses/by-nc/4.0/) which permits any noncommercial use, distribution, and reproduction in any medium, provided the original author(s) and the source are credited.
} 

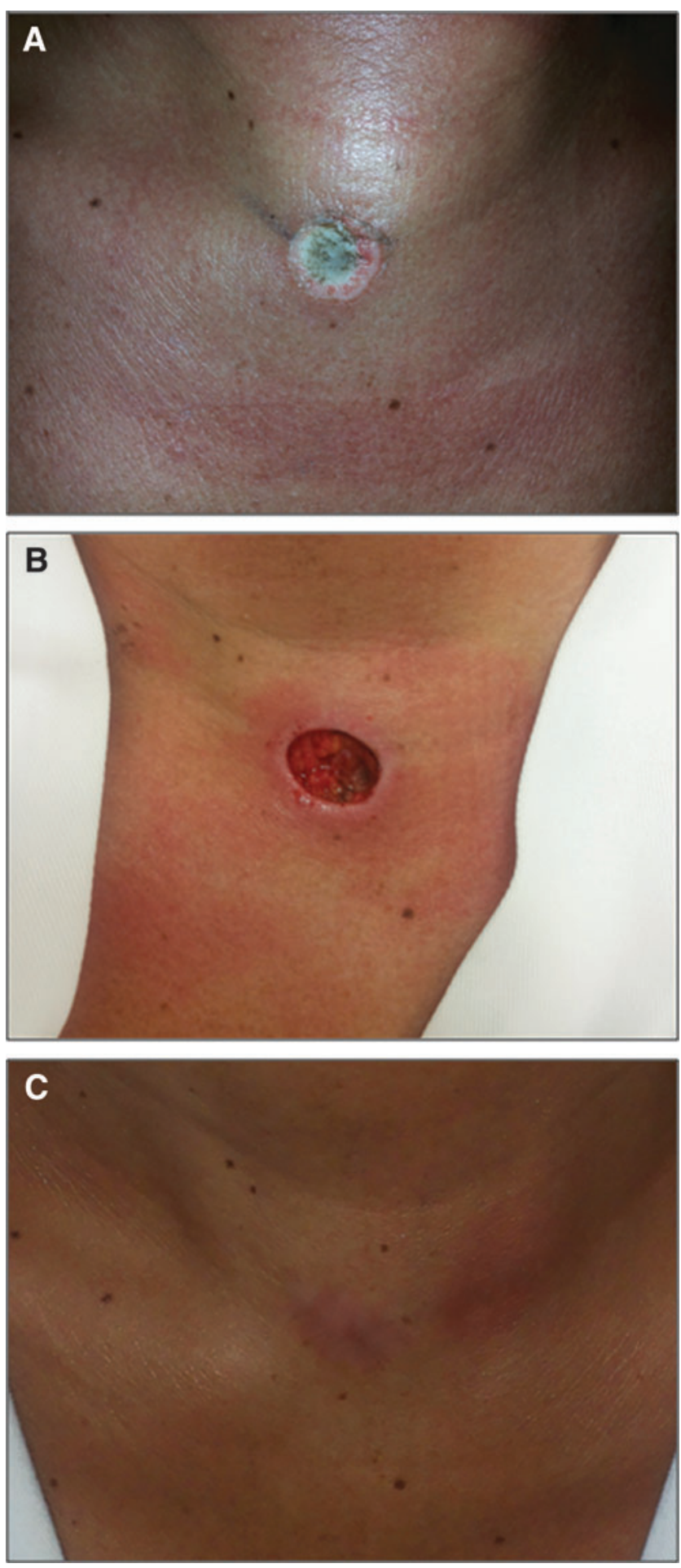

FIG. 1. (A) Baseline image of the radiofrequency ablation-induced full-thickness burn, which looks like a coin, with a maximum diameter of $1.5 \mathrm{~cm}$ and a charred white necrotic core. (B) Image of the neck after the surgical debridement of the wound. (C) Image of the final appearance of the neck scar. Color images are available online at www.liebertpub.com/thy
In order to prevent such a complication, it is important to keep the active needle tip within the nodule. To do so, it is recommended to use the transisthmic approach whenever possible. It can also be useful to inject cold fluid in the subcutaneous layers under the puncture site in order to create a wheal that will raise the skin and increase the distance from the nodule (we generally do that when injecting the lidocaine). It is also suggested (3) to apply an ice bag on the skin next to the puncture site during the ablation. In any case, it is important to keep in mind that conscious sedation may delay the detection of complications, and it is important to pay attention when treating superficial nodules in lean patients, where the active needle tip is more likely to come into contact with the skin. In cases when a skin burn develops, specific care will facilitate the wound healing process in order to achieve a satisfactory esthetic result.

\section{Author Disclosure Statement}

None of the authors has any commercial association that might create a conflict of interest in connection with submitted manuscripts.

\section{References}

1. Bernardi S, Dobrinja C, Fabris B, Bazzocchi G, Sabato N, Ulcigrai V, Giacca M, Barro E, De Manzini N, Stacul F 2014 Radiofrequency ablation compared to surgery for the treatment of benign thyroid nodules. Int J Endocrinol 2014:934595.

2. Dobrinja C, Bernardi S, Fabris B, Eramo R, Makovac P, Bazzocchi G, Piscopello L, Barro E, de Manzini N, Bonazza D, Pinamonti M, Zanconati F, Stacul F 2015 Surgical and pathological changes after radiofrequency ablation of thyroid nodules. Int J Endocrinol 2015:576576.

3. Baek JH, Lee JH, Sung JY, Bae JI, Kim KT, Sim J, Baek SM, Kim Y, Shin JH, Park JS, Kim DW, Kim J, Kim E, Jung SL, Na DG 2012 Complications encountered in the treatment of benign thyroid nodules with US-guided radiofrequency ablation: a multicenter study. Radiology 262:335-342.

4. Kim YS, Rhim H, Tae K, Park DW, Kim ST 2006 Radiofrequency ablation of benign cold thyroid nodules: initial clinical experience. Thyroid 16:361-367.

5. Na DG, Lee JH, Jung SL, Kim JH, Sung JY, Shin JH, Kim EK, Lee JH, Kim DW, Park JS, Kim KS, Baek SM, Lee Y, Chong S, Sim JS, Huh JY, Bae JI, Kim KT, Han SY, Bae MY, Kim YS, Baek JH; Korean Society of Thyroid Radiology (KSThR); Korean Society of Radiology 2012 Radiofrequency ablation of benign thyroid nodules and recurrent thyroid cancers: consensus statement and recommendations. Korean J Radiol 13:117-125.

Address corresponding to:

Stella Bernardi, MD, PhD

Department of Medical, Surgical and Health Sciences University of Trieste Cattinara Teaching Hospital, Strada di Fiume 34100 Trieste Italy

E-mail: stella.bernardi@aots.sanita.fvg.it/ shiningstella@gmail.com 